\title{
LEGITIMIDADE DA CONTRATAÇÃO DE FAMILIARES DE CANDIDATOS EM CAMPANHAS ELEITORAIS
}

\author{
Legitimacy of Hiring Candidates' Family Members in Election Campaigns
}

(iD) Adriana Morales Alencar Souto

Resumo: Este artigo trata da contratação de familiares de candidatos em campanhas eleitorais, objetivando discutir a legitimidade ou não desse ato. Busca-se estabelecer a diferenciação entre os termos legalidade e legitimidade e, ao mesmo tempo, apresentar um rápido panorama quanto à utilização de recursos públicos no financiamento de campanhas eleitorais, para depois apresentar decisões judiciais de cinco Tribunais Regionais Eleitorais que analisaram a contratação, com recursos públicos, de familiares em campanhas eleitorais. Para sua realização, foi feita a opção de uma abordagem qualitativa, do tipo bibliográfica e documental. Foram consultados livros e artigos científicos de doutrinadores (MARTINS, 2020; MELLO, 2019; MENDES; VALE apud CANOTILHO et al., 2018; FRANÇA, 1995; BULOS, 2005, dentre outros). Também foi feita pesquisa de jurisprudência no site do Tribunal Superior Eleitoral. Concluiu-se que tal possibilidade contraria o conjunto normativo constitucional-administrativo existente, embora não exista proibição expressa na legislação eleitoral.

Palavras-chave: Legalidade. Legitimidade. Financiamento. Campanha eleitoral. Parentes.

\begin{abstract}
This article deals with hiring candidates' family members in electoral campaigns, aiming to discuss the legitimacy of this act. The aim is to establish a differentiation between the terms legality and legitimacy and, at the same time, present an overview of the use of public resources in the financing of electoral campaigns, to later present judicial decisions of five Regional Electoral Courts that analyzed the hiring of family members in election campaigns with public resources. The study adopted a qualitative approach using bibliographic and documentary research, including the work of prominent scholars in legal doctrine. In addition, a case law search was carried out on the website of the Superior Electoral Court. It was concluded that hiring candidates' family members in electoral campaigns contradicts the existing constitutional-administrative normative provisions, although there is no express prohibition in the electoral legislation.
\end{abstract}

Keywords: Legality. Legitimacy. Financing. Election campaign. Family members.

Artigo recebido em 19 fev. 2021 e aprovado em 28 jun. 2021

Editor responsável: Luiz Magno Pinto Bastos Junior

DOI: https://doi.org/10.53323/resenhaeleitoral.v25i1.126 


\section{Introdução}

A utilização de recursos públicos no financiamento de campanhas eleitorais já é realizada há algum tempo no sistema eleitoral brasileiro. Doutrinariamente, classifica-se o modelo de financiamento eleitoral brasileiro em misto, por admitir não apenas recursos públicos, mas também recursos de origem privada em campanhas.

Após o Supremo Tribunal Federal vedar a doação financeira de pessoas jurídicas para campanhas eleitorais, observou-se uma significativa alteração na composição dos recursos em dinheiro que financiam as eleições: enquanto nas eleições de 2014, 46\% dos recursos arrecadados procederam de pessoas jurídicas, nas eleições de $2018,80,51 \%$, e nas eleições de $2020,60,41 \%$, de todos os recursos financeiros movimentados tiveram origem pública.

Essa significativa alteração não poderia vir desacompanhada de regras e preceitos próprios e de uma nova maneira de utilização desses recursos. Como qualquer outro bem público, a aplicação de dinheiro público em campanhas eleitorais traz consigo a incidência de um arcabouço normativo aplicável à Administração Pública em geral, o qual está fincado em princípios constitucionais.

Mediante o cenário apresentado, o presente artigo buscou responder à seguinte indagação: é legítima a contratação de familiares em campanhas eleitorais com recursos oriundos dos fundos públicos de financiamento (Fundo Partidário e Fundo Especial de Financiamento de Campanha)? Foram consultados livros e artigos científicos de doutrinadores que, de alguma forma, já escreveram sobre o tema. Também foi feita pesquisa de jurisprudência no site do Tribunal Superior Eleitoral.

Serão apresentados posicionamentos de cinco Tribunais Regionais Eleitorais que já trataram da referida temática, incluindo o de Mato Grosso do Sul, até mesmo em razão da contextualização espacial da questão, e, ao final, será demonstrado se referido gasto eleitoral guarda coerência com o sistema jurídico constitucional-administrativo vigente.

Metodologicamente, a opção foi por realizar uma pesquisa que se sustenta na abordagem qualitativa, pois procurará compreender as informações e analisá-las no contexto em que foram produzidas. A pesquisa realizada classifica-se quanto ao tipo, em aplicada, por apresentar aplicações práticas sobre o assunto, e exploratória, pois buscou-se explicitar o proble- 
ma a partir de levantamento bibliográfico e decisões judiciais. Quanto aos procedimentos técnicos, pautou-se em pesquisas de natureza bibliográfica e documental, já que foi desenvolvido com base em material já elaborado, constituído principalmente de livros, artigos científicos e decisões judiciais. Pretende-se que este artigo possa corroborar para a ampliação de subsídios para análises sobre a temática abordada.

\section{Legalidade e legitimidade: referências teóricas}

O que é legal, nem sempre é legítimo e vice-versa, de acordo com os conceitos adotados para este artigo. Também com os antônimos ilegal e ilegítimo é possível construir variáveis para a afirmação inicial. Os dois conceitos povoam o senso comum e algumas vezes são utilizados de maneira equivocada, razão pela qual se faz necessária sua diferenciação, posto que não se confundem.

A legalidade vem estampada no inciso II do artigo $5^{\circ}$ da Constituição Federal de 1988, como a garantia de que ninguém será obrigado a fazer ou deixar de fazer alguma coisa senão em virtude de lei. Tal lei, como bem lembra Martins (2020, p. 744), "se refere à lei no sentido lato ou amplo", abarcando assim qualquer "ato normativo do poder público, envolvendo decretos, portarias, resoluções, medidas provisórias, etc.”. No entanto, Mello (2019, p. 105-106) assevera que, para proibir ou impor um comportamento, a Administração Pública deve estar previamente embasada em lei que lhe faculte vedar ou exigir algo a quem quer que seja.

Nesse ponto, ampliando o entendimento sobre lei em sentido formal, ensinam Mendes e Vale (apud CANOTILHO et al., 2018) que regras e princípios, como comandos normativos emitidos pela Constituição, também direcionam a atividade estatal:

É certo que não apenas a lei em sentido formal, mas também a Constituição emite comandos normativos direcionados à atividade estatal. Esses comandos normativos podem possuir a estrutura de regras ou de princípios. No primeiro caso, a prescrição detalhada e fechada da conduta deontologicamente determinada estabelece uma estrita vinculação dos Poderes Públicos. Por exemplo, a regra da anterioridade tributária descrita pelo enunciado normativo do art. 150, III, da Constituição. No caso dos princípios, a estrutura normativa aberta deixa certas margens de 'livre deliberação' (freie Ermessen) aos Pode- 
res do Estado. Assim ocorre quando a Constituição, em seu art. 37, determina a obediência, pela Administração Pública, à moralidade e à impessoalidade ${ }^{1}$.

Por seu turno, legitimidade, na lição de Bonavides (apud FRANÇA, 1995), "é a legalidade acrescida de sua valoração", em razão de "ter sua concepção influenciada pelas crenças de um tempo que orientam a manifestação do consentimento e da obediência"².

Destaca-se a lição de Bobbio (apud BULOS, 2005, p. 127), para quem "legitimidade e legalidade são atributos do poder, embora contenham qualidades diferentes deste, pois a legitimidade é a qualidade do título do poder, e a legalidade, a qualidade de seu exercício".

Evidenciada a diferença entre os dois termos, na sequência serão abordados os tipos de financiamento de campanha e como os recursos públicos são utilizados em tal finalidade.

\section{Recursos públicos para campanhas eleitorais: tipos e fins de financiamento}

O Fundo Especial de Financiamento de Campanha (FEFC) foi criado pela Lei n⿳⺈ 13.487/2017, que introduziu o artigo 16-C à Lei das Eleições. Após o Supremo Tribunal Federal vedar o financiamento de campanhas eleitorais por pessoas jurídicas ${ }^{3}$, o FEFC, fundo constituído por re-

${ }^{1}$ MENDES, Gilmar Ferreira; VALE, André Rufino do. Comentários ao art. 5o, II, Constituição Federal. In: CANOTILHO, J. J. Gomes; MENDES, Gilmar Ferreira; SARLET, Ingo Wolfgang; STRECK, Lenio Luiz; LEONCY, Léo Ferreira. Comentários à constituição do Brasil. 2. ed. São Paulo: Saraiva, 2018.

${ }^{2}$ BONAVIDES, Paulo. Ciência política. 10. ed. São Paulo: Malheiros, 1986. p. 115 In: FRANÇA, Edilson Alves de. Legalidade e legitimidade: distinção. 1995. Revista Eleitoral, v. 8, n. 2, jul./dez. 1995. Tribunal Regional Eleitoral do Rio Grande do Norte. Disponível em: http://bibliotecadigital.tse.jus.br/xmlui/bitstream/handle/bdtse/2949/1995_franca_legalidade_legitimidade_distincao.pdf?sequence=1. Acesso em: 25 jul. 2020.

${ }^{3}$ Ementa: Direito Constitucional e Eleitoral. Modelo normativo vigente de financiamento de campanhas eleitorais. Lei das eleições, arts. 23, \ $1^{\circ}$, incisos i e ii, 24 e 81 , caput e $\ 1^{\circ}$. Lei orgânica dos partidos políticos, arts. 31, 38, inciso iii, e 39, caput e $\int 5^{\circ}$. Critérios de doações para pessoas jurídicas e naturais e para o uso de recursos próprios pelos candidatos. Preliminares. Impossibilidade jurídica do pedido. Rejeição. Pedidos de declaração parcial de inconstitucionalidade sem redução de texto (itens e.1.e e.2). Sentença de perfil aditivo (item e.5). Técnica de decisão amplamente utilizada por cortes constitucionais. Atuação normativa subsidiária e excepcional do Tribunal Superior Eleitoral, somente se legitimando em 
cursos públicos, buscou garantir recursos suficientes para o financiamento das campanhas eleitorais.

Conforme ensina Banhos ${ }^{4}$ (apud COSTA et al., 2018, p. 149), até a importante decisão do STF no julgamento da $\mathrm{ADI} \mathrm{n}^{\circ}$ 4.650, as campanhas eleitorais foram financiadas com doações de pessoas físicas e de pessoas jurídicas, além dos valores oriundos do Fundo Partidário. "Historicamente, doações de pessoas jurídicas eram em valor muito superior às realizadas por pessoas físicas. Os custos das campanhas também vinham aumentando drasticamente, principalmente a partir das doações de empresas. O quadro não era nada bom." Diante desse novo cenário, o aporte de recursos públicos para o financiamento de campanhas eleitorais cresceu sobremaneira.

O modelo de financiamento adotado no Brasil é o misto. Além dos recursos públicos oriundos do Fundo Especial de Financiamento de Campanha e do Fundo Partidário, são permitidas doações de pessoas físicas, utilização de recursos dos próprios candidatos e arrecadação por meio da venda de bens e realização de eventos com a finalidade específica de

caso de inertia deliberandi do congresso nacional para regular a matéria após o transcurso de prazo razoável (in casu, de dezoito meses). Inadequação da via eleita. Improcedência. Pretensões que veiculam ultraje à lei fundamental por ação, e não por omissão. Mérito. Ofensa aos princípios fundamentais democrático e da igualdade política. Cumulação de pedidos de adi e de adi por omissão em uma única demanda de controle concentrado de constitucionalidade. Viabilidade processual. Premissas teóricas. Postura particularista e expansiva da suprema corte na salvaguarda dos pressupostos democráticos. Sensibilidade da matéria, afeta que é ao processo político-eleitoral. Autointeresse dos agentes políticos. Ausência de modelo constitucional cerrado de financiamento de campanhas. Constituição-moldura. Normas fundamentais limitadoras da discricionariedade legislativa. Pronunciamento do Supremo Tribunal Federal que não encerra o debate constitucional em sentido amplo. Diálogos institucionais. Última palavra provisória. Mérito. Doação por pessoas jurídicas. inconstitucionalidade dos limites previstos na legislação ( $2 \%$ do faturamento bruto do ano anterior à eleição). Violação aos princípios democrático e da igualdade política. Captura do processo político pelo poder econômico. "Plutocratização" do prélio eleitoral. limites de doação por naturais e uso de recursos próprios pelos candidatos. Compatibilidade material com os cânones democrático, republicano e da igualdade política. Ação direta de inconstitucionalidade julgada parcialmente procedente (BRASIL, 2016).

${ }^{4}$ BANHOS, Sérgio Silveira. O financiamento de campanhas à luz da vedação de doações por parte de pessoas jurídicas: análise, reflexões e desafios para as eleições de 2018. In: COSTA, Daniel Castro Gomes da; MIRANDA, Jorge; FONSECA, Leonardo Campos Soares da; CARVALHO NETO, Tarcísio Vieira de (coord.). Direito Eleitoral Comparado. Belo Horizonte: Fórum, 2018. p. 149. Disponível em: https://www.forumconhecimento.com.br/livro/1760/1842/16865. Acesso em: 13 ago. 2020. 
aplicação dos recursos na campanha eleitoral. Não obstante, o volume de recursos públicos utilizados é percentualmente muito superior ao de recursos privados. Para ilustrar, dos mais de cinco bilhões de reais em recursos financeiros movimentados nas eleições gerais de 2018, 80,51\% foram recursos públicos e $19,49 \%$ foram recursos privados ${ }^{5}$. Nas eleições municipais de 2020, 60,41\% dos mais de oito bilhões movimentados nas campanhas eleitorais foram recursos públicos ${ }^{6}$. Ocorre que essa equação nem sempre foi assim.

Pondera Schlickmann (apud FUX et al., 2018, p. 59-60) que, nas eleições de 2014, a última antes da decisão do STF na ADI no 4.650/DF, que vedou o financiamento de campanhas eleitorais por pessoas jurídicas, $46 \%$ do total de recursos financeiros arrecadados foi proveniente de financiamento empresarial ${ }^{7}$. Acresça-se à tal percentual outras fontes privadas de financiamento, como doações de pessoas físicas e recursos dos próprios candidatos. Não obstante, antes da Lei n⿳⼈ㄹ 13.487/2017, ainda que em proporção inferior, a presença de recursos públicos no financiamento de campanhas eleitorais sempre foi uma constante.

Esse grande volume de dinheiro envolvido em campanhas eleitorais, principalmente de origem pública, suscita preocupações e, acrescenta Soares (apud FUX et al., 2018, p. 39), o tema "desperta a necessidade do estabelecimento de regulação e fiscalização eficazes, para evitar que o abuso de recursos materiais possa prejudicar a legitimidade das eleições.” O autor ainda pondera que a regulação da matéria é de suma importância porque se,

${ }^{5}$ Dados divulgados pelo Tribunal Superior Eleitoral no endereço http://www.tse.jus. br/eleicoes/estatisticas/estatisticas-eleitorais revelam que o total de recursos financeiros movimentados nas Eleições Gerais de 2018 foi de R\$ 5.904.441.886,27. Desses, 80,51\% foram recursos públicos $(\mathrm{R} \$ 4.753 .856 .165,54)$ e $19,49 \%(\mathrm{R} \$ 1.150 .585 .720,73)$ foram recursos privados.

${ }^{6}$ Nas eleições municipais de 2020, segundo dados divulgados pelo TSE em https:// www.tse.jus.br/eleicoes/estatisticas/estatisticas-eleitorais, foram movimentados $\mathrm{R} \$$ 5.209.203.562,53 em recursos públicos, de um total de recursos financeiros no montante de $\mathrm{R} \$ 8.623 .147 .048,35$.

${ }^{7}$ SCHLICKMANN, Denise Goulart. O fim das doações empresariais: o impacto do julgamento da ADI 4.650 pelo Supremo Tribunal Federal sobre o financiamento das campanhas eleitorais no Brasil. In: FUX, Luiz; PEREIRA, Luiz Fernando Casagrande; AGRA, Walber de Moura; PECCININ, Luiz Eduardo (coord.). Financiamento e prestação de contas: tratado de Direito Eleitoral. v. 5. Belo Horizonte: Fórum, 2018. p. 59-60. Disponível em: https://www.forumconhecimento.com.br/livro/1697/ 1778/5562. Acesso em: 13 ago. 2020. 
de um lado, o dinheiro é essencial para realizar as campanhas, de outro, "é preciso garantir a igualdade de oportunidades entre os candidatos e partidos políticos, bem como evitar o abuso do poder econômico, que, uma vez ocorrido, prejudica a legitimidade do pleito." ${ }^{8}$

Nesse sentido, ensina Zovatto (2005, p. 299), que o financiamento público em campanhas eleitorais "é concedido com a intenção de fazer com que as operações financeiras dos partidos, suas receitas e suas despesas, corram por vias transparentes, conhecidas e sujeitas aos órgãos de controle e fiscalização do erário público. A ideia é que, por se tratar de recursos dos contribuintes, os princípios de transparência e de controle sejam garantidos de melhor maneira."

A utilização da coisa pública, lato sensu, aqui entendida como bens, valores, servidores, etc., atrai a incidência de normas de Direito Público. Com as campanhas eleitorais não seria diferente. Ao envolver recursos públicos no financiamento de campanhas, é certo que os princípios e regras de Direito Público não podem ser afastados ou esquecidos, estando eles descritos, ou não, nos regulamentos de eleição editados a cada pleito pelo Tribunal Superior Eleitoral por meio de resoluções.

O poder normativo do Tribunal Superior Eleitoral, além da função interna corporis de auto-organização, visa regulamentar a legislação eleitoral, "de modo a permitir o legítimo trâmite das eleições", segundo Lins (2014, p. 3). Para referido autor, pretende-se que o TSE complemente a legislação eleitoral no que for necessário para o bom disciplinamento do pleito. Esse é o conteúdo do artigo 105 da Lei nº 9.504/1997 (Lei das Eleições). Nesse sentido, também esclarece Gonçalves Júnior (2016, p. 71):

A função normativa da Justiça Eleitoral lhe garante não só realizar normas para organizar seu aparato administrativo e os procedimentos eleitorais, mas também, expedir normas dirigidas à sociedade política para que os valores materiais eleitorais sejam plenamente alcançados. Do contrário, seria admitir a negação da eficácia destes valores.

\footnotetext{
${ }^{8}$ SOARES, Michel Bertoni. Financiamento eleitoral exclusivamente público? Ponderações entre o financiamento público e o financiamento privado. In: FUX, Luiz; PEREIRA, Luiz Fernando Casagrande; AGRA, Walber de Moura; PECCININ, Luiz Eduardo (coord.). Financiamento e prestação de contas: tratado de Direito Eleitoral. v. 5. Belo Horizonte: Fórum, 2018. p. 39. Disponível em: https://www.forumconhecimento.com.br/ livro/1697/1778/5558. Acesso em: 23 ago. 2020.
} 
Obviamente, as resoluções editadas no âmbito do poder normativo do TSE não podem contrariar a Constituição ou a lei. Na lição de Lins (2014, p. 4), referido Tribunal "deve levar em consideração a legislação eleitoral que já existe, pois com ela não deve divergir".

Se a Teoria Geral do Direito ensina que as resoluções são atos normativos secundários, elas não podem contrariar os princípios e regras que estão acima delas. Da mesma forma, o silêncio, em uma resolução acerca da forma de utilização de recursos públicos em campanhas eleitorais, não autoriza que tais valores sejam aplicados ao arrepio das normas de Direito Público sedimentadas na Constituição e na lei.

Assim como Midas, que na Mitologia Grega transformava em ouro tudo o que tocava, da mesma maneira acontece com a coisa pública: a sua utilização atrai a aplicação de um conjunto normativo de regras e princípios de Direito Público, que visam assegurar, em última análise, a legalidade, a impessoalidade, a moralidade, a publicidade e a eficiência.

\section{Contratação de familiares de candidatos em campanhas eleitorais: uma análise sobre decisões judiciais sobre o tema}

A partir de todas as considerações feitas anteriormente, será passada à análise de um ponto específico quanto à aplicação de recursos financeiros do Fundo Partidário e do Fundo Especial de Financiamento de Campanha: a contratação de familiares dos próprios candidatos para atuarem nas campanhas eleitorais. Serão apresentadas decisões proferidas pelo Tribunal Superior Eleitoral (TSE) e por cinco Tribunais Regionais Eleitorais, as quais foram encontradas no sistema de busca de jurisprudência do Tribunal Superior Eleitoral ${ }^{9}$, com a utilização randômica das seguintes palavras: prestação, contas, parentes, familiares, parentesco, família, contratação, eleição, campanha, eleitoral, gastos.

O Tribunal Regional Eleitoral de Santa Catarina apresentou uma posição legalista quanto ao tema da contratação de familiares para as campanhas eleitorais, tanto para a contratação direta da pessoa física ${ }^{10}$, quanto para a contratação de empresa que tenha parentes dos candidatos no qua-

${ }^{9}$ A pesquisa de jurisprudência do Tribunal Superior Eleitoral está disponível em: http:/ / www.tse.jus.br/jurisprudencia/decisoes/jurisprudencia.

${ }^{10}$ Prestação de Contas n⿳ 0601851-23.2018.624.0000 - Florianópolis/SC, ACÓRDÃO n⿳ำ 33778, de 27/09/2019, Relator JUIZ FERNANDO LUZ DA GAMA LOBO D’EÇA, Publicação: DJE - Diário de JE, Tomo 175, Data 30/09/2019, p. 4. 
dro societário ${ }^{11}$. Independentemente, se os recursos utilizados na contratação adviessem dos fundos públicos ${ }^{12}$ ou de outros recursos ${ }^{13}$, a posição do Tribunal foi a de não considerar irregulares tais contratações, em razão de "não haver dispositivo na legislação eleitoral que proíba a contratação, pelos candidatos, de serviços prestados por parentes"14, argumento que foi utilizado em todas as decisões consultadas, nas quais as contas prestadas foram aprovadas com ressalvas.

Nesse mesmo sentido, o Tribunal Regional Eleitoral do Rio Grande do Norte, ainda por ocasião do julgamento de contas de campanha das eleições municipais de 2016, não vislumbrou óbice quanto à contratação de parentes com recursos públicos do Fundo Partidário. Atendo-se ao que determinava o regulamento vigente para as referidas eleições ${ }^{15}$, a Corte potiguar concluiu pela regularidade dos gastos, tendo em vista que houve o efetivo registro na prestação de contas e a juntada da correspondente documentação comprobatória. Além disso, não vislumbrou nos autos prova de fraude ou conluio com o fim de apropriação indevida de recursos do Fundo Partidário. Dessa maneira, concluiu que os processos de prestação de contas se limitam à averiguação da regularidade contábil da campanha,

${ }^{11}$ Prestação de Contas nº 0601559-38.2018.624.0000 - Florianópolis/SC, ACÓRDÃO nº 34272, de 03/03/2020, Relator JUIZ JAIME PEDRO BUNN, Publicação: DJE - Diário de JE, Tomo 32, Data 09/03/2020, p. 5.

Prestação de Contas nº 0601856-45.2018.624.0000 - Florianópolis/SC, ACÓRDÃO no 33465, de 10/12/2018, Relator JUIZ WILSON PEREIRA JUNIOR, Publicação: DJE Diário de JE, Tomo 224, Data 12/12/2018, p. 9.

${ }^{12}$ Prestação de Contas nำ 601862-52.2018.624.0000 - Florianópolis/SC, ACÓRDÃO ํํำ 33461, de 06/12/2018, Relator ANTONIO FERNANDO SCHENKEL DO AMARAL E SILVA Publicação: PSESS - Publicado em Sessão, Data 06/12/2018.

Prestação de Contas no 0601752-53.2018.624.0000 - Florianópolis/SC, ACÓRDÃO no 34369, de 03/06/2020, Relator CELSO KIPPER Publicação: DJE - Diário de JE, Tomo 96, Data 17/06/2020, p. 1.

${ }^{13}$ Prestação de Contas n⿳o 601357-61.2018.624.0000 - Florianópolis/SC, ACÓRDÃO no 33440, de 30/11/2018, Relator ANTONIO FERNANDO SCHENKEL DO AMARAL E SILVA, Publicação: PSESS - Publicado em Sessão, Data 30/11/2018.

${ }^{14}$ Acórdãos no 33440, de 30/11/2018 (PSESS - Publicado em Sessão, Data 30/11/2018); no 34369, de 08/06/2020 (DJE - Diário de JE, Tomo 96, Data 17/06/2020, p. 1), no 33461, de 06/12/2018 (PSESS - Publicado em Sessão, Data 06/12/2018).

${ }^{15}$ Resolução TSE no $23.463 / 2015$. 
não sendo possível "a reprovação das contas com base em suposta ilicitude, quando esta não esteja amparada em elemento concreto dos autos." 16

Por seu turno, o Tribunal Regional Eleitoral do Rio Grande do Sul abordou, reflexamente, a contratação de familiares para as campanhas eleitorais em processo no qual ficou evidenciado que o candidato contratou a si próprio. O órgão técnico apontou a irregularidade em parecer preliminar e houve a devolução espontânea dos recursos públicos do FEFC, antes do julgamento do processo. Tal conduta fez com que o Regional apontasse a irregularidade como ressalva nas contas. Não obstante, os argumentos lançados no voto denotam a reprovação da contratação de parentes em campanhas eleitorais pelo Tribunal gaúcho, pois, mesmo não havendo norma proibitiva expressa, tal conduta contraria os princípios da moralidade e da impessoalidade:

As normas que regulam a contabilidade eleitoral não coíbem, expressamente, que candidatos, bem como seus parentes, forneçam bens e serviços às próprias campanhas eleitorais. O entendimento por tal vedação advém de extensão dos princípios inerentes à administração pública às verbas advindas do FEFC, cuja utilização ocorreu de modo inaugural nas campanhas de 2018. Malgrado eventualmente afrontosa aos princípios da moralidade e da impessoalidade, o prestador buscou a correção da falha antes do julgamento das contas, procedendo ao ressarcimento dos valores correspondentes ao erário. ${ }^{17}$

Noutro viés, com uma interpretação sistemática das regras eleitorais e princípios constitucionais, o Tribunal Regional Eleitoral de Rondônia rechaçou o argumento de que a falta de proibição legal expressa legitimaria a contratação de parentes com recursos públicos para campanhas eleitorais. Para o TRE/RO, a administração de recursos públicos exige transparência na aplicação do dinheiro, sem desvirtuamento dos propósitos de atendimento ao interesse público enraizado nas campanhas eleitorais, razão pela qual o gerenciamento desses recursos reclama que se observe os princípios

\footnotetext{
${ }^{16}$ Recurso Eleitoral nº 248-36.2016.6.20.0067 - Nísia Floresta/RN, ACÓRDÃO nº 190, de 03/05/2018, Relator JUIZ FEDERAL FRANCISCO GLAUBER PESSOA ALVES, Publicação: DJE de 08/05/2018, p. 213.

${ }^{17}$ Prestação de Contas n⿳ㅜ 602572-56.2018.621.0000 - Porto Alegre/RS, ACÓRDÃO de 09/12/2019, Relator DES. ELEITORAL SILVIO RONALDO SANTOS DE MORAES, Publicação: PSESS - Publicado em Sessão.
} 
norteadores da gestão pública, especialmente a moralidade e a impessoalidade.

Assim, na linha do entendimento da Corte, havendo recursos públicos aplicados em campanhas eleitorais, o norte a ser seguido é a Constituição Federal da República. Por tal razão, os princípios que regem a Administração Pública devem estar presentes quanto à destinação de tais verbas. Além disso, o Tribunal não tira o princípio da eficiência da mira, ao destacar que a contratação de familiares poderia abalar a qualidade dos serviços prestados:

Com efeito, ainda que não haja vedação legal expressa, não há de se admitir a contratação de parentes para atuar na campanha do candidato, pagos com recursos públicos, como ocorreu no caso destes autos, haja vista essa prática, além de contrariar a moralidade e impessoalidade, desatende também aos princípios da economicidade e eficiência, pois não se pode aferir com a necessária segurança se efetivamente os serviços contratados foram prestados com qualidade, eficiência e preço adequado, uma vez que ajustes desse jaez se aperfeiçoam entre familiares, o que abala a confiabilidade e transparência das contas de campanha. ${ }^{18}$

O mesmo Regional manteve esse entendimento ao apreciar processo de prestação de contas, em que os gastos realizados com a contratação de parentes, ou de empresas cujos sócios sejam familiares do candidato, não foram pagos no período eleitoral e seriam assumidos pelo partido político como dívida de campanha e, consequentemente, seriam liquidados com recursos do Fundo Partidário. Ponderou-se que os mesmos princípios que regem a administração pública, previstos na Constituição Federal, devem estar presentes na destinação de verbas do Fundo Partidário. Ademais, não haveria violação à autonomia dos partidos políticos, pois em se tratando de verba pública, tal autonomia está adstrita aos termos da Constituição. Assim, concluiu o Tribunal que "realmente não se pode admitir que verba pública (Fundo Partidário) seja utilizada para pagamento de despesas não

\footnotetext{
${ }^{18}$ Prestação de Contas nº 0601664-69.2018.6.22.0000 - Porto Velho/RO, ACÓRDÃO no 26, de 02/03/2020, Relator JUIZ ILISIR BUENO RODRIGUES, Publicação: DJE 042, de $4 / 03 / 2020$, p. 7.
} 
pagas durante a campanha e cujos fornecedores sejam parentes ou o próprio candidato como sócio." 19

A jurisprudência do Tribunal Regional Eleitoral de Mato Grosso do Sul é a mais farta quando se trata de contratação de familiares com recursos públicos para campanhas eleitorais. Inicialmente, desconsiderando qualquer irregularidade na contratação de parentes ${ }^{20}$ ou simplesmente não se pronunciando sobre tal inconsistência apontada em relatórios técnicos ${ }^{21}$ , a mudança na jurisprudência da Corte aconteceu a partir de 23 de julho de 2019, no julgamento do processo de Prestação de Contas nº 0601182 03.2018.6.12.0000 22 .

No referido leading case, do total de recursos financeiros movimentados e oriundos do Fundo Especial de Financiamento de Campanha, $50 \%$ foi aplicado na contratação de dois filhos da candidata, sendo que um deles ainda era servidor público municipal e estava afastado do serviço público por estar no gozo de auxílio-doença. Além disso, há expressa disposição no voto de que não houve comprovação nos autos de que os familiares efetivamente desempenharam qualquer atividade na campanha eleitoral, tendo a prestadora de contas apenas se limitado a refutar tal inconsistência com o argumento de que não há qualquer vedação a tal prática na legislação eleitoral.

Unanimemente, a Corte sul-mato-grossense decidiu por não avalizar a utilização de recursos públicos em proveito do próprio candidato e de seus familiares, entendendo que a contratação de parentes até terceiro grau, ou de empresas que tenham sócios com relação de parentesco com os candidatos, é incompatível com o conjunto jurídico-constitucional bra-

\footnotetext{
${ }^{19}$ Prestação de Contas no 0601221-21.2018.6.22.0000 - Porto Velho/RO, ACÓRDÃO 14, de 03/04/2020, Relator JUIZ MARCELO STIVAL, Publicação: DJE 068, de 07/04/2020, p. $9-10$.

${ }^{20}$ Prestação de Contas n⿳o 0601176-93.2018.6.12.0000 - Campo Grande/MS, Decisão de 29/01/2019, Relator JUIZ CEZAR LUIZ MIOZZO, Publicação: DJE - Diário da Justiça Eleitoral, Tomo 2228, Data 15/07/2019, p. 11-12.

${ }^{21}$ Prestação de Contas nº 0601153-50.2018.6.12.0000 - Campo Grande/MS, Decisão de 11/07/2019, Relator JUIZ JOSE HENRIQUE NEIVA DE CARVALHO E SILVA, Publicação: DJE - Diário da Justiça Eleitoral, Tomo 2122, Data 31/01/2019, p. 8-11.

22 Prestação de Contas nº 0601182-03.2018.6.12.0000 - Campo Grande/MS, ACÓRDÃO no 060118203, de 23/07/2019, Relator(a) DANIEL CASTRO GOMES DA COSTA, Publicação: DJE - Diário da Justiça Eleitoral, Tomo 2237, Data 26/07/2019, p. 15-28.
} 
sileiro e implica ofensa direta aos princípios constitucionais da moralidade administrativa e da impessoalidade.

A partir desse julgamento, em vários outros também foi aplicado pelo TRE/MS o mesmo entendimento, sendo considerada irregular a contratação de familiares em campanhas eleitorais, com a consequente determinação de devolução dos valores ao Tesouro Nacional. Cite-se os seguintes processos: 0601365-71.2018.6.12.0000²3, 0601121-45.2018.6.12.0000 ${ }^{24}, \quad 0601126-67.2018 .6 .12 .0000^{25}, \quad 0601374-33.2018 .6 .12 .0000^{26}, \quad$ 060139339.2018.6.12.000027, 0601372-63.2018.6.12.0000 ${ }^{28}, 0601165-64.2018 .6 .12 .0000^{29}$, 0601163-94.2018.6.12.0000 ${ }^{30}, \quad 0601544-05.2018 .6 .12 .0000^{31}$,

0601224

${ }^{23}$ Prestação de Contas nº 0601365-71.2018.6.12.0000 - Campo Grande/MS, ACÓRDÃO no 060136571, de 07/10/2019, Relator(a) ABRÃO RAZUK, Publicação: DJE - Diário da Justiça Eleitoral, Tomo 2291, Data 15/10/2019, p. 6-8.

${ }^{24}$ Prestação de Contas nº 0601121-45.2018.6.12.0000 - Campo Grande/MS, ACÓRDÃO n⿳o 060112145, de 22/11/2019, Relator(a) DANIEL CASTRO GOMES DA COSTA, Publicação: DJE - Diário da Justiça Eleitoral, Tomo 2319, Data 26/11/2019, p. 86-90.

${ }^{25}$ Prestação de Contas nํ 0601126-67.2018.6.12.0000 - Campo Grande/MS, ACÓRDÃO no 060112667, de 14/11/2019, Relator(a) JUIZ DJAILSON DE SOUZA, Publicação: DJE - Diário da Justiça Eleitoral, Tomo 2316, Data 21/11/2019, p. 15-17.

${ }^{26}$ Prestação de Contas nº 0601374-33.2018.6.12.0000 - Campo Grande/MS, ACÓRDÃO $\mathrm{n}^{\circ}$ 060137433, de 14/11/2019, Relator(a) JUIZ DJAILSON DE SOUZA, Publicação: DJE - Diário da Justiça Eleitoral, Tomo 2314, Data 19/11/2019, p. 9-11.

${ }^{27}$ Prestação de Contas nº 0601393-39.2018.6.12.0000 - Campo Grande/MS, ACÓRDÃO nº 060139339, de 22/11/2019, Relator(a) DANIEL CASTRO GOMES DA COSTA, Publicação: DJE - Diário da Justiça Eleitoral, Tomo 2319, Data 26/11/2019, p. 73-77.

${ }^{28}$ Prestação de Contas nº 0601372-63.2018.6.12.0000 - Campo Grande/MS, ACÓRDÃO nº 060137263, de 16/10/2019, Relator(a) ABRÃO RAZUK, Publicação: DJE - Diário da Justiça Eleitoral, Tomo 2294, Data 18/10/2019, p. 6-7.

${ }^{29}$ Prestação de Contas nº 0601165-64.2018.6.12.0000 - Campo Grande/MS, ACÓRDÃO n⿳o 060116564, de 23/09/2019, Relator(a) DANIEL CASTRO GOMES DA COSTA, Publicação: DJE - Diário da Justiça Eleitoral, Tomo 2278, Data 24/09/2019, p. 3-6.

${ }^{30}$ Prestação de Contas nº 0601163-94.2018.6.12.0000 - Campo Grande/MS, ACÓRDÃO $\mathrm{n}^{\circ}$ 060116394, de 29/11/2019, Relator(a) DANIEL CASTRO GOMES DA COSTA, Publicação: DJE - Diário da Justiça Eleitoral, Tomo 2327, Data 06/12/2019, p. 14-17.

${ }^{31}$ Prestação de Contas nº 0601544-05.2018.6.12.0000 - Campo Grande/MS, ACÓRDÃO no 060154405, de 29/11/2019, Relator(a) DANIEL CASTRO GOMES DA COSTA, Publicação: DJE - Diário da Justiça Eleitoral, Tomo 2325, Data 04/12/2019, p. 9-14. 
52.2018.6.12.0000 32 ,0601401-16.2018.6.12.0000, $0601239-21.2018 .6 .12 .0000^{34}$, 0601545-87.2018.6.12.0000

Finalmente, quanto ao Tribunal Superior Eleitoral, embora não tenha enfrentado diretamente o assunto nos mesmos moldes das decisões anteriormente expostas (aplicação de recursos públicos para a contratação de familiares em campanhas eleitorais), a Corte já se pronunciou, em julgamento de prestação de contas anual de partido, que "se entende como contrária à moralidade e à economicidade a contratação de serviços com empresas que tenham em seu quadro societário pessoas com vínculo de parentesco com candidatos ou dirigentes partidários, muito mais flagrante se revela a contratação direta de familiares." 36

\section{Considerações finais}

A vedação do financiamento empresarial em campanhas eleitorais inaugurou uma nova realidade a partir das eleições de 2018, na qual houve um aporte de recursos públicos muito mais volumoso do que outrora utilizado. Esses recursos, justamente por serem de origem pública, trouxeram consigo um arcabouço normativo, que não era tão evidente em eleições passadas.

É certo de que a utilização de bens e recursos ${ }^{37}$ públicos atrai a incidência do normativo constitucional-administrativo correspondente. Ao bônus da disponibilidade para a utilização com fins eleitorais de recursos públicos do Fundo Partidário e do Fundo Especial de Financiamento de

32 Prestação de Contas nº 0601224-52.2018.6.12.0000 - Campo Grande/MS, ACÓRDÃO no 060122452, de 22/10/2019, Relator(a) ABRÃO RAZUK, Publicação: DJE - Diário da Justiça Eleitoral, Tomo 2299, Data 25/10/2019, p. 12-15.

${ }_{33}$ Prestação de Contas nº 0601401-16.2018.6.12.0000 - Campo Grande/MS, ACÓRDÃO no 060140116, de 06/11/2019, Relator(a) ABRÃO RAZUK, Publicação: DJE - Diário da Justiça Eleitoral, Tomo 2312, Data 14/11/2019, p. 6-8.

${ }^{34}$ Prestação de Contas no 0601239-21.2018.6.12.0000 - Campo Grande/MS, ACÓRDÃO no 060123921, de 14/11/2019, Relator(a) JUIZ DJAILSON DE SOUZA, Publicação: DJE - Diário da Justiça Eleitoral, Tomo 2316, Data 21/11/2019, p. 30-32.

${ }^{35}$ Prestação de Contas no 0601545-87.2018.6.12.0000 - Campo Grande/MS, ACÓRDÃO $\mathrm{n}^{\circ}$ 060154587, de 14/11/2019, Relator(a) JUIZ DJAILSON DE SOUZA, Publicação: DJE - Diário da Justiça Eleitoral, Tomo 2316, Data 21/11/2019, p. 18-20.

${ }^{36}$ Prestação de Contas n⿳0 0000228-15.2013.6.00.0000 - BRASÍLIA - DF, Acórdão de 26/04/2018, Relator(a) Min. Rosa Weber, Publicação: DJE - Diário de justiça eletrônico, Tomo 110, Data 06/06/2018, p. 57-58.

${ }^{37}$ Lato sensu. 
Campanha, corresponde o ônus de se submeter ao sistema jurídico que rege a administração pública, de forma especial e destacada aos princípios estampados no caput do artigo 37 da Constituição Federal.

Assim, diante dos fundamentos adotados, não se sustenta o argumento de que a falta de proibição expressa na legislação eleitoral ou nas resoluções editadas pelo Tribunal Superior Eleitoral legitimaria a contratação de familiares em campanhas eleitorais. Isso porque, se são recursos públicos que estão sendo utilizados, não se pode fechar os olhos para o que está previsto na Constituição Federal, principalmente aos princípios da moralidade, da economicidade e da impessoalidade.

A partir do sistema jurídico-administrativo presente na Constituição Federal, é plenamente exigível que a pessoa que tenha contato com a coisa pública aja com probidade e ética, para que não ocorra desvirtuamento em proveito próprio e favorecimentos pessoais, ao arrepio da impessoalidade, moralidade e isonomia, que encardem a esfera pública. E se recursos públicos são utilizados em campanhas, todo esse arcabouço principiológico e normativo aplicável à administração pública alcança a esfera eleitoral.

Por tais razões, mesmo não havendo vedação legal expressa, conclui-se pela impossibilidade da contratação de familiares com recursos públicos para campanhas eleitorais, por ofensa direta aos princípios constitucionais da moralidade, impessoalidade, economicidade e eficiência. Tal conclusão estende-se, também, à contratação de empresas que tenham familiares dos candidatos nos seus quadros societários, e qualquer outro tipo de utilização desses recursos públicos, que possam caracterizar favorecimentos pessoais e sobreposição do interesse privado ao público.

Independentemente da proporção de recursos utilizados que tais contratações representem, se houve a utilização de recursos públicos em proveito próprio ou de parentes, resta caracterizada a violação ao sistema jurídico constitucional-administrativo. Ponderações quanto à representatividade de tal uso no conjunto de todos os demais recursos movimentados nas campanhas podem servir ao julgador em cada caso concreto. 


\section{Referências}

BANHOS, Sérgio Silveira. O financiamento de campanhas à luz da vedação de doações por parte de pessoas jurídicas: análise, reflexões e desafios para as eleições de 2018. In: COSTA, Daniel Castro Gomes da; MIRANDA, Jorge; FONSECA, Leonardo Campos Soares da; CARVALHO NETO, Tarcísio Vieira de (coord.). Direito Eleitoral Comparado. Belo Horizonte: Fórum, 2018. Disponível em: https://www.forumconhecimento.com.br/livro/ 1760/1842/16865. Acesso em: 13 ago. 2020. p. 148.

BRASIL. STF. ADI 4650, Rel. Min. Luiz Fux. Julgamento em 17 setembro 2015. DJe de 24 fevereiro 2016.

BRASIL. STF. Tribunal Regional Eleitoral de Mato Grosso do Sul. PC Prestação de Contas n 0601182-03.2018.6.12.0000 - Campo Grande/MS, ACÓRDÃO no 060118203, de 23/07/2019, Relator DANIEL CASTRO GOMES DA COSTA, Publicação: DJE - Diário da Justiça Eleitoral, Tomo 2237, Data 26/07/2019, p. 15-28.

BRASIL. STF. Tribunal Regional Eleitoral de Rondônia. PC - Prestação de Contas n⿳⺈ 0601664-69.2018.6.22.0000 - Porto Velho/RO, ACÓRDÃO no 26, de 02/03/2020, Relator JUIZ ILISIR BUENO RODRIGUES, Publicação: DJE 042, de 04/03/2020, p. 7.

BRASIL. STF. Tribunal Regional Eleitoral de Rondônia. PC - Prestação de Contas n⿳ำ 0601221-21.2018.6.22.0000 - Porto Velho/RO, ACÓRDÃO no 14, de 03/04/2020, Relator JUIZ MARCELO STIVAL, Publicação: DJE 068, de 07/04/2020, p. 9-10.

BRASIL. STF. Tribunal Regional Eleitoral do Rio Grande do Norte. Recurso Eleitoral nº 248-36.2016.6.20.0067 - Nísia Floresta/RN, ACÓRDÃO nº 190, de 03/05/2018, Relator JUIZ FEDERAL FRANCISCO GLAUBER PESSOA ALVES, Publicação: DJE de 08/05/2018, Página 213.

BRASIL. STF. Tribunal Regional Eleitoral do Rio Grande do Sul. PC - Prestação de Contas no 602572-56.2018.621.0000 - Porto Alegre/RS, ACÓRDÃO de 09/12/2019, Relator DES. ELEITORAL SILVIO RONALDO SANTOS DE MORAES, Publicação: PSESS - Publicado em Sessão.

BRASIL. STF. Tribunal Superior Eleitoral. PC - Prestação de Contas $\mathrm{n}^{\circ}$ 0000228-15.2013.6.00.0000 - BRASÍLIA - DF, Acórdão de 26/04/2018, Relator(a) Min. Rosa Weber, Publicação: DJE - Diário de Justiça Eletrônico, Tomo 110, Data 06/06/2018, Página 57-58. 
BULOS, Uadi Lammêgo. Constituição federal anotada. 6. ed. rev. atual. e ampl. São Paulo: Saraiva, 2005.

CANOTILHO, J. J. Gomes; MENDES, Gilmar Ferreira; SARLET, Ingo Wolfgang; STRECK, Lenio Luiz; LEONCY, Léo Ferreira. Comentários à constituição do Brasil. 2. ed. São Paulo: Saraiva, 2018.

FRANÇA, Edilson Alves de. Legalidade e legitimidade: distinção. 1995. Revista Eleitoral, v. 8, n. 2, jul./dez. 1995. Tribunal Regional Eleitoral do Rio Grande do Norte. Disponível em: http://bibliotecadigital.tse.jus.br/ xmlui/bitstream/ handle/bdtse/2949/1995_franca_legalidade_legitimidade_ distincao.pdf?sequence=1. Acesso em: 25 jul. 2020.

GONÇALVES JÚNIOR, Carlos. A atividade normativa da justiça eleitoral. Rio de Janeiro: Lumen Juris, 2016.

LINS, Rodrigo Martiniano Ayres. Direito eleitoral descomplicado. 2. ed. Rio de Janeiro: Ferreira, 2014.

MARTINS, Flávio. Curso de direito constitucional. 4. ed. São Paulo: Saraiva Educação, 2020.

MELLO, Celso Antônio Bandeira de. Curso de direito administrativo. 34. ed. rev. e atual. São Paulo: Malheiros, 2019.

MENDES, Gilmar Ferreira; VALE, André Rufino do. Comentários ao art. 5, II, Constituição Federal. In: CANOTILHO, J. J. Gomes; MENDES, Gilmar Ferreira; SARLET, Ingo Wolfgang; STRECK, Lenio Luiz; LEONCY, Léo Ferreira. Comentários à constituição do Brasil. 2. ed. São Paulo: Saraiva, 2018.

SCHLICKMANN, Denise Goulart. O fim das doações empresariais: o impacto do julgamento da ADI 4.650 pelo Supremo Tribunal Federal sobre o financiamento das campanhas eleitorais no Brasil. In: FUX, Luiz; PEREIRA, Luiz Fernando Casagrande; AGRA, Walber de Moura; PECCININ, Luiz Eduardo (coord.). Financiamento e prestação de contas: tratado de direito eleitoral. v. 5. Belo Horizonte: Fórum, 2018. Disponível em: https://www. forumconhecimento.com.br/livro/1697/1778/5562. Acesso em: 13 ago. 2020.

SOARES, Michel Bertoni. Financiamento eleitoral exclusivamente público? Ponderações entre o financiamento público e o financiamento privado. In: FUX, Luiz; PEREIRA, Luiz Fernando Casagrande; AGRA, Walber de Moura; PECCININ, Luiz Eduardo (coord.). Financiamento e prestação de contas: tratado de direito eleitoral. v. 5. Belo Horizonte: Fórum, 2018. Disponível em: https://www.forumconhecimento.com.br/livro/1697/ 1778/5558. Acesso em: 23 ago. 2020. 
ZOVATTO, Daniel. Financiamento dos partidos e campanhas eleitorais na América Latina: uma análise comparada. Opinião Pública, Campinas, v. 11, n. 2, p. 287-336, out. 2005. Disponível em: http://www.scielo.br/scielo. php?script $=$ sci_arttext\&pid $=$ S0104 $=62762005000200002-\& \operatorname{lng}=$ en\&nrmiso. Acesso em: 14 ago. 2020. https://doi.org/10.1590/S010462762005000200002 .

Adriana Morales Alencar Souto - Analista Judiciário/Área Judiciária no Tribunal Regional Eleitoral de Mato Grosso do Sul desde 2009. Graduada em Direito pela Universidade Federal de Mato Grosso do Sul (2006). Pós-Graduada em Direito Constitucional (2007) e em Direito Tributário (2012) pela Universidade para o Desenvolvimento do Estado e Região do Pantanal. Pós-Graduada em Direito Eleitoral pela Faculdade Insted (2021). E-mail: adriana. alencar@tre-ms.jus.br. ORCID: https://orcid.org/0000-0002-0475-6978. 